\title{
OUVIDORIA DA SUPERINTENDÊNCIA REGIONAL DO DEPARTAMENTO NACIONAL DE INFRAESTRUTURA DE TRANSPORTES DA PARAÍBA: OLHAR DOS SERVIDORES E USUÁRIOS
}

\author{
Rita de Cássia Santa Cruz Monteiro \\ Luiz Antonio Coêlho da Silva²
}

\begin{abstract}
Resumo
As Ouvidorias Públicas iniciam o seu processo de institucionalização no Brasil a partir de 1986, e desde então vêm sofrendo mudanças estruturais, funcionais, de princípios, marcos regulatórios, modos de acesso do cidadão e níveis de autonomia. As Ouvidorias Públicas vêm se fortalecendo nas últimas décadas como instituições que auxiliam o cidadão em suas relações com o Estado, facilitando o diálogo com a Administração Pública. O presente estudo buscou analisar a atuação da Ouvidoria da Superintendência Regional do Departamento Nacional de Infraestrutura de Transportes da Paraíba (DNIT) por meio do olhar dos servidores internos do órgão e usuários do sistema da Ouvidoria. Nesse sentido, foram aplicados questionários aos servidores do órgão e aos cidadãos que acionaram a Ouvidoria no ano de 2015. Nos aspectos metodológicos, a pesquisa foi, quanto aos fins, exploratória e descritiva; quanto aos meios, adotou-se a pesquisa bibliográfica, documental e de campo. Concluiu-se assim que a percepção dos servidores e usuários do sistema está focada no cumprimento dos prazos de resposta pela Ouvidoria e marcada pela falta de divulgação da Ouvidoria como canal de participação social, o que merece uma iniciativa de melhoria por parte dos gestores do órgão e Ouvidoria Sede.
\end{abstract}

Palavras-chave: Ouvidoria Pública. Participação popular. DNIT.

\section{DOI:10.37814/2594-5068.2018v1.p187-198}

1 Pós-graduada em Gestão Pública pelo Instituto Federal da Paraíba- IPPB. Pós-graduada em Gestão Pública com Ênfase em Projetos pela Fundação Getúlio Vargas- FGV. MBA em Marketing pela FGV. Graduada em Administração de Empresas pela UFPB. Analista Administrativo do DNIT.

2 Graduado em Economia e em Ciências Contábeis. Especialista em Economia Solidária e em Gestão Pública. Doutor em Ciências Sociais. Área: Política, Desenvolvimento e Sociedade. Professor Adjunto da UFCG (Gestão Pública). 


\begin{abstract}
Public Ombudsman's Office started their institutionalization process in Brazil in 1986, and since then has been going through some changes such as structural, functional, of principles, regulatory frameworks, citizen access modes and levels of autonomy. The Public Ombudsman's Office has been strengthening over the last decades as institutions that assist citizens in their relations with the state, facilitating dialogue with the Public Administration. The current study aimed to know the perception of the Regional Superintendence's Ombudsman's Office of Paraiba's Infrastructure and Transport Department by the servers and users in 2015. In this sense, questionnaires were applied along the organ servers and citizens that triggered the Ombudsman's Office in 2015. In the methodological aspects, the survey was about the exploratory and descriptive purposes and as to the tactics bibliographical, documental and field research were the chosen ones. It is therefore concluded that the perception of servers and users of the system is focused on meeting the deadlines for replying of the Ombudsman's Office and marked by the lack of promotion of Ombudsman's Office as social participation channel, which deserves improvement initiative by managers of the organ and Ombudsman's Office's Head Office.
\end{abstract}

Keywords: Public Ombudsman's Office. Popular participation. DNIT. 


\section{INTRODUÇÃO}

O despertar da sociedade civil e a participação ativa dos cidadãos no processo de desenvolvimento social constituem fenômenos marcantes da nossa história atual, o que tem contribuído para solidificar as práticas e processos democráticos, quando o cidadão passa a atuar, fiscalizar e tomar iniciativas através de canais que lhe são abertos na esfera pública.

Torna-se imprescindível que a Administração Pública esteja apta a garantir de modo efetivo a participação popular e o controle social nas atividades públicas no Brasil. Por meio da participação na gestão pública, os cidadãos podem intervir na tomada de decisões administrativas ao orientar a Administração na adoção de medidas que realmente atendam ao interesse público e, ao mesmo tempo, ao exercer controle sobre a ação do Estado, exigindo que o gestor público preste contas de sua atuação.

Neste contexto, a Ouvidoria representa um canal de atendimento ao cidadão, uma espécie de convite para que a sociedade participe da vida administrativa das entidades públicas, tecendo críticas ou elogios, através dos quais a Administração Pública pode construir um sistema de feedback para aprimorar o rumo de suas ações.

Sendo assim, as Ouvidorias Públicas institucionalizadas no Brasil, de uma forma geral, enfrentam dificuldades na execução de suas atividades, o que compromete a construção de uma identidade institucional e enfraquece sua legitimação junto à sociedade e também a seu público interno.

O presente estudo foi realizado na Ouvidoria da Superintendência Regional do Departamento Nacional de Infraestrutura de Transporte (DNIT), no Estado da Paraíba, no ano de 2015.

Considerando que o estudo busca analisar a atuação da Ouvidoria do DNIT na Paraíba, tem-se então como questão central da pesquisa: Como os servidores do DNIT na Paraíba e usuários do seu sistema de Ouvidoria percebem o trabalho desse órgão de controle social?

\section{OBJETIVOS}

\section{Objetivo Geral}

- Analisar a atuação do trabalho da Ouvidoria a partir do olhar dos servidores do órgão e usuários do sistema da Ouvidoria no ano de 2015.

\section{Objetivos Específicos}

- Apresentar as atividades desenvolvidas na Ouvidoria da Superintendência do DNIT.

- Identificar as dificuldades enfrentadas pela Ouvidoria no desenvolvimento de suas atividades.

- Conhecer os resultados alcançados pela Ouvidoria do DNIT.

- Sugerir ações de melhorias na atuação da Ouvidoria Regional do DNIT na Paraíba. 


\section{JUSTIFICATIVA}

O presente estudo nasceu do interesse da pesquisadora, servidora do DNIT e representante da Ouvidoria no Estado da Paraíba, em analisar o trabalho prestado pela Ouvidoria da Superintendência Regional da Paraíba por meio daqueles que a utilizam como ferramenta de participação e controle social no âmbito da atuação do DNIT neste Estado. Acredita-se que o estudo seja relevante, pois possibilitará detectar gargalos e contribuir com o intuito de tornar a Ouvidoria uma ferramenta a mais de gestão.

A base metodológica da pesquisa consistiu na coleta de dados por meio da revisão bibliográfica e aplicação de questionários. O universo da pesquisa foi a Superintendência Regional do DNIT da Paraíba. A abordagem do estudo foi qualitativa, e na análise dos dados foi utilizado o método estatístico-descritivo, com o uso da estatística básica.

\section{GESTÃO PÚBLICA E SEUS INSTRUMENTOS DE CONTROLE}

A partir da década de 1980, o mundo passou por profundas transformações, como a globalização, a dinâmica tecnológica, a publicitação da área pública e as inovadas formas de organização do trabalho. Esta nova realidade econômica e social se apresentou e impôs mudanças de comportamento da Administração Pública por meio da sua gestão.

Com a promulgação da Constituição Federal em 1988, evoluíram os conceitos de democracia e participação popular, que passaram a contemplar a necessidade por melhor gestão dos recursos públicos e melhor controle da sociedade sobre a formulação de políticas públicas.

Para Idalberto CHIAVENATO (2000), o conceito de controle consistia em checar se os objetivos almejados estavam sendo alcançados por quem os estava realizando. Podendo, ainda, ser o controle um guia para as atividades fim previamente determinadas e acompanhar sua realização.

Dentre os instrumentos de controle de que dispõe a Administração Pública, é possível citar os controles interno, externo e o social, que surgem com o processo de redemocratização do país durante a década de 1980-90.

\subsection{Controles (Interno, Externo e Social) na Administração Pública}

A Administração Pública, no exercício de suas funções, sujeita-se ao controle por parte dos Poderes Legislativo e Judiciário, além de exercer, ela mesma, o controle sobre os próprios atos.

Marcelo ALEXANDRINO e Vicente PAULO (2012) conceituam o controle administrativo como um conjunto de meios estabelecidos pelo ordenamento jurídico para que, através da própria Administração Pública, dos Poderes Judiciário, Legislativo e de toda a população, com o auxílio dos órgãos especializados em controle, possam fiscalizar, orientar e revisar a atuação dos órgãos da Administração Pública e seus agentes em todos os Poderes da União.

Quando o agente controlador integra a própria Administração, chamamos de controle inter-

190 | Revista Científica da Associação Brasileira de Ouvidores/Ombudsman - Ano 1 - nº 1 - 2017/2018 
no. Quando o controle é efetuado por órgão, ente ou instituição exterior à estrutura da Administração, como o controle realizado por instituições políticas (Poder Legislativo), por instituições técnicas (Tribunais de Contas) e por instituições precipuamente jurídicas (Judiciário), chamamos de controle externo.

Outrossim, necessário se faz referenciar o accountability como instrumento de controle social. Esse conceito, segundo as explicações de Valdecir PASCOAL (2008), surgiu nos países anglo-saxões em meados de 1980, definido por alguns autores como sendo o "dever de prestar contas". Outros autores preferiam conceituá-lo como o "dever de transparência”, e havia ainda aqueles que alegavam ser o accountability o "dever de eficiência daqueles responsáveis pela realização das atividades financeiras do Estado".

DE MARIO (2011) aponta as Ouvidorias como sendo exímios instrumentos de prestação de contas (accountability) quando, por meio delas, os interesses dos cidadãos são levados em consideração. Instrumentos estes que se referem à democracia representativa buscando diminuir a distância entre representantes e representados, promovendo governos a par das necessidades e anseios de seus cidadãos.

\section{CONTEXTUALIZAÇÃO DAS OUVIDORIAS PÚBLICAS E SEU PAPEL COMO INSTÂN- CIA DE CONTROLE E PARTICIPAÇÃO SOCIAL}

No século XIX, com a ampliação dos direitos do cidadão diante do poder do Estado, surgiu na Suécia a primeira expressão formal de Ouvidoria com a figura do Ombudsman, que em sueco significa "representante do povo". Apenas no final do século XX as Ouvidorias chegaram à América Latina. Em 1986, inicia-se o processo de institucionalização das Ouvidorias Públicas no Brasil e, desde então, elas vêm sofrendo mudanças estruturais, funcionais, de princípios, marcos regulatórios, tutelas jurídicas, formas de seleção, competências, modos de acesso do cidadão, níveis de autonomia e de hierarquia.

Como instrumento legal relacionado à atuação das Ouvidorias Públicas, pode-se citar o Decreto $\mathrm{n}^{\circ}$ 8.243, de 23 de maio de 2014, que institui, no âmbito do Poder Executivo Federal, a Política Nacional de Participação Social e o Sistema Nacional de Participação Social. O Decreto define o papel das Ouvidorias Públicas e determina que as Ouvidorias do Poder Executivo Federal observem as diretrizes da Ouvidoria-Geral da União (OGU), ligada à Controladoria-Geral da União (CGU). Esse Decreto fortalece e enfatiza a atuação das Ouvidorias no âmbito do Poder Executivo quando afirma serem elas uma instância de controle e participação social, com vistas ao aprimoramento da gestão pública.

\section{DISCUSSÃO SOBRE O PAPEL DAS OUVIDORIAS PÚBLICAS E DO OUVIDOR COMO AGENTE DE TRANSFORMAÇÃO NA GESTÃO PÚBLICA}

A atuação das Ouvidorias Públicas está respaldada no art.37, §3º da Constituição de 1988, que diz: 
$\S 3^{\circ}$ A lei disciplinará as formas de participação do usuário na Administração Pública direta e indireta, regulando especificamente:

I - as reclamações relativas à prestação dos serviços públicos em geral, asseguradas a manutenção de serviços de atendimento ao usuário e a avaliação periódica, externa e interna, da qualidade dos serviços;

II - o acesso dos usuários a registros administrativos e a informações sobre atos de governo, observado o disposto no art. $5^{\circ}, \mathrm{X}$ e XXXIII;

III - a disciplina da representação contra o exercício negligente ou abusivo de cargo, emprego ou função na Administração Pública.

O papel do Ouvidor é muito importante para a gestão, pois ele deve defender os direitos do cidadão junto à Administração Pública. Ele deve ser um aliado na luta pela efetivação dos direitos dos cidadãos que buscam os serviços públicos, assim como na busca pela solução de conflitos.

A conduta do Ouvidor deve ser baseada nos princípios éticos e constitucionais da Administração Pública, uma vez que ele precisa ser um aliado na luta pela efetivação dos direitos dos cidadãos que buscam os serviços públicos.

\section{PROCEDIMENTOS METODOLÓGICOS}

\subsection{Tipo de Pesquisa}

Quanto aos fins, a pesquisa é exploratória e descritiva. Exploratória porque no DNIT não foram localizados estudos acerca das opiniões dos públicos externo e interno da Ouvidoria sobre a atuação desta no âmbito das ações desenvolvidas pelo órgão no Estado da Paraíba. Descritiva, pois a partir das informações coletadas nos questionários, pode-se conhecer um pouco da percepção dos usuários do sistema da Ouvidoria e servidores do órgão na Paraíba, além de descrever o funcionamento da Ouvidoria do DNIT.

Quanto aos meios, a pesquisa foi bibliográfica, documental e de campo. Bibliográfica porque utilizou livros impressos e artigos publicados na internet de autores da área de Ouvidorias Públicas e Privadas, assim como documentos divulgados por órgãos como a Controladoria-Geral da União (CGU), onde está inserida a Ouvidoria-Geral da União (OGU). Como coleta de dados foram aplicados questionários com os públicos interno e externo, com 21 (vinte e uma) questões estruturadas e abertas sobre acesso, atendimento e satisfação no atendimento prestado pela Ouvidoria do DNIT.

Salientamos que a pesquisa foi aplicada com o consentimento formal do Superintendente Regional do DNIT na Paraíba.

\subsection{Universo e Amostra}

O estudo foi realizado no âmbito da Superintendência Regional da Paraíba, abrangendo as unidades locais de Santa Rita, Campina Grande e Patos (municípios paraibanos), no ano de 2015, somando-se 67 (sessenta e sete) servidores.

A Ouvidoria DNIT trabalha com dois tipos de público: o demandante externo e o interno. 
O demandante externo é aquele cidadão que utiliza os serviços nos modais rodoviário, ferroviário e hidroviário estabelecidos dentro dos limites da competência institucional do DNIT. E o demandante interno compreende os servidores e funcionários do órgão.

\subsection{Instrumentos e Procedimentos da Coleta de Dados}

Foram utilizadas como referência para esta pesquisa as demandas da Ouvidoria no ano de 2015. Vale salientar que o sistema da Ouvidoria apresentou problemas técnicos, tendo permanecido inoperante por quase 6 (seis) meses, quando as demandas passaram a ser recepcionadas em sua grande maioria pelo e-mail geral da Ouvidoria e pelo e-mail interno na Superintendência, o que pode ter provocado a redução das demandas da Ouvidoria a partir do segundo semestre do respectivo ano.

Foram enviados por e-mail 25 (vinte e cinco) questionários para os cidadãos que fizeram uso do sistema on-line da Ouvidoria; destes, apenas 6 (seis) foram respondidos. Ressalta-se o fato de a Ouvidoria ainda receber um número considerável de demandas anônimas, o que dificultou o envio de mais questionários.

\section{APRESENTAÇÃO DOS RESULTADOS, ANÁLISE E DISCUSSÃO}

\subsection{Perfil dos Entrevistados}

Fizeram parte da pesquisa 27 servidores (público interno) e 6 usuários do Sistema da Ouvidoria (público externo), totalizando 33 participantes.

\subsection{Público Externo: Usuários do Sistema da Ouvidoria}

Quanto aos usuários externos, os questionários foram aplicados apenas àqueles que utilizaram o sistema on-line da Ouvidoria ou que enviaram suas demandas por meio do e-mail interno da Ouvidoria.

\subsubsection{Quantas vezes a Ouvidoria foi acionada}

Neste questionamento, 5 (cinco) entrevistados responderam que acionaram a Ouvidoria do DNIT apenas uma vez e 1 (um) entrevistado respondeu que, no ano de 2015, acionou a Ouvidoria por cinco vezes.

\subsubsection{Tempo de resposta das demandas pela Ouvidoria}

O tempo de resposta foi considerado satisfatório por todos que responderam ao questionário. 
A Ouvidoria do DNIT adota o tempo de resposta como sendo de 20 dias corridos em concordância com o prazo estipulado (LAl).

\subsubsection{Facilidade no acesso ao sistema on-line da Ouvidoria}

O sistema on-line foi considerado como sendo de fácil acesso pelos usuários do sistema, com ressalva para um entrevistado que respondeu que o primeiro acesso foi tranquilo, contudo em outras vezes teve dificuldades. Acredita-se que esta dificuldade relatada deve-se à inoperância do sistema no período de junho a novembro de 2015.

\subsubsection{Acesso à Ouvidoria por outro canal de atendimento além do sistema on-line}

Não há registro de recebimento de demandas na Ouvidoria da Superintendência Regional do DNIT na Paraíba no período de março de 2011 a novembro de 2015 por carta. Há demandas por telefone e pessoalmente, registradas na Ouvidoria Sede.

Até setembro de 2015, a Superintendência Regional da Paraíba não dispunha de um número de telefone específico para a Ouvidoria, nem de sala individualizada.

\subsubsection{Resposta satisfatória}

A insatisfação na resposta recebida da Ouvidoria pelos seus usuários foi de 33\%, o que merece ser considerado como uma crítica construtiva. Como justificativa, um entrevistado alegou que os termos da resposta eram técnicos e que não conseguia entender algumas siglas. O cuidado com as respostas precisa ser redobrado, considerando que a linguagem usada precisa ser clara e de fácil entendimento, evitando-se o uso de termos técnicos do órgão.

\subsubsection{Demanda da Ouvidoria levada em consideração pelo DNIT}

As demandas de cinco dos seis usuários que foram questionados foram levadas em consideração pelo órgão, o que representou $83 \%$.

\subsubsection{Acionaria novamente a Ouvidoria?}

Considerando que todos os respondentes acionariam novamente a Ouvidoria, fica reforçada a ideia de que esse canal deve continuar atuando, contando ainda com maior acessibilidade e aprimoramento constante do seu atendimento.

194 | Revista Científica da Associação Brasileira de Ouvidores/Ombudsman - Ano 1 - no 1 - 2017/2018 


\subsubsection{Sugestão, elogio ou reclamação ao atendimento da Ouvidoria}

Como elogio tivemos o tempo de resposta e o atendimento; sugeriu-se que o acesso ao sistema fosse facilitado, houvesse melhor divulgação e que o sistema aceitasse anexos.

\subsection{Público Interno: Servidores do DNIT na Paraíba \\ 8.3.1 Acionamento da Ouvidoria}

Dos 27 (vinte e sete) servidores que responderam ao questionário, apenas 4 (quatro) acionaram a Ouvidoria, o que representa $14,81 \%$ de acesso à Ouvidoria pelos servidores do órgão.

\subsubsection{Resposta satisfatória}

Nesta questão houve equilíbrio quanto à satisfação em relação à resposta, com $50 \%$ (cinquenta por cento) considerando ter sido satisfatória sua resposta e $50 \%$ (cinquenta por cento) considerando não ter sido.

\subsubsection{Demanda levada em consideração pelo órgão}

Dos 4 (quatro) servidores que fizeram uso da Ouvidoria, 3 (três) responderam que suas demandas não foram levadas em consideração pelo órgão. Dado importante a ser considerado para análise da Ouvidoria.

\subsubsection{Acionaria novamente a Ouvidoria?}

Houve novamente equilíbrio nas respostas quanto a um novo acionamento da Ouvidoria do DNIT.

\subsubsection{Facilidade no acesso ao sistema on-line da Ouvidoria}

Apesar de 92,59\% dos servidores não terem acionado a Ouvidoria do DNIT, 55,56\% responderam que o sistema on-line é de fácil acesso. Isto pode significar que conhecem o sistema ou já o localizaram no site do DNIT. Contudo, 2 (dois) servidores alegaram não saber da existência do sistema on-line da Ouvidoria. Dado relevante para que a Ouvidoria possa ser mais divulgada internamente. 


\subsubsection{Acesso à Ouvidoria por outro canal de atendimento além do sistema on-line, e se obteve resposta}

Dos 27 entrevistados, 4 (quatro) afirmaram já ter acionado a Ouvidoria por outro acesso; 13 (treze) responderam que não; 2 (dois) nunca solicitaram os serviços da Ouvidoria, e 1 (um) alegou não saber da existência de outros canais de atendimento, o que ratifica a urgente necessidade de divulgação da Ouvidoria e de seus canais de atendimento no órgão.

\subsubsection{Considera que a Ouvidoria tem autonomia dentro do DNIT}

O fato de $48,15 \%$ dos servidores do DNIT terem considerado que a Ouvidoria tem autonomia, contra $25,93 \%$ que consideraram que ela não tem autonomia, e os demais que não souberam ou não responderam, deve ser discutido e analisado pelo próprio órgão, até porque era preciso saber o que seria autonomia para os 13 (treze) servidores que responderam que a Ouvidoria tem autonomia.

\subsubsection{Considera a Ouvidoria um canal de participação social}

A Ouvidoria foi considerada um canal de participação social por $81,48 \%$, mas ainda surgem respostas de que "o órgão não é" e de que "pelo menos deveria ser". Uma espécie de descrença na atuação da Ouvidoria dentro do órgão.

\subsubsection{Como considera a atuação da Ouvidoria no DNIT}

Nesta questão, talvez por ser uma das mais subjetivas, surgiram respostas diversas, mas que trazem informações para a melhoria da atuação da Ouvidoria, como a sua própria divulgação internamente.

\subsubsection{Sugestão, elogio ou reclamação ao atendimento prestado pela Ouvidoria}

Dentre os elogios, tivemos a qualidade das informações prestadas e o atendimento dentro do prazo, a atenção no atendimento também foi citada. Foi sugerido que a Ouvidoria fosse independente. Percebe-se que houve sugestões relevantes que podem servir de indicativos de melhoria na atuação da Ouvidoria. 


\subsubsection{Acrescentar algum assunto que não foi abordado no questionário}

Dentre os assuntos que foram abordados neste quesito, pode-se dar ênfase à solicitação de divulgação da Ouvidoria dentro e fora do DNIT como canal de melhoria para o órgão, de forma que os dirigentes possam apoiar as ações da Ouvidoria.

\section{CONSIDERAÇÕES FINAIS E SUGESTÕES}

Percebe-se, diante do exposto, que a Ouvidoria da Superintendência Regional da Paraíba encontra-se em um processo de construção de imagem e que o fator de maior visibilidade tanto para o público interno (servidores) quanto para o público externo (usuários do sistema da Ouvidoria) é o cumprimento no prazo das respostas. Fato este que merece destaque, mas que não pode ser o seu maior valor.

O acesso ao sistema da Ouvidoria foi considerado fácil pelos públicos interno e externo. Contudo, houve sugestões de que o link da Ouvidoria poderia ter maior visibilidade no site do DNIT, o que se acredita ser possível. Ademais, quando foi perguntado se a demanda teria sido levada em consideração pelo DNIT, houve um dado significativo nas respostas de 3 (três) servidores quando estes afirmaram que suas demandas não foram levadas em consideração pelo órgão. Este pode ser um dos motivos pelos quais a Ouvidoria do DNIT não seja tão acionada pelos seus servidores.

Em observância ao que constou do questionário, têm-se então algumas sugestões: 1) estabelecer um programa de divulgação interna da Ouvidoria, abrangendo principalmente as Unidades Locais para que ela seja entendida como um canal de melhoria para a gestão do órgão; 2) divulgar a Ouvidoria para a sociedade por meio de adesivos nos carros oficiais; 3) disponibilizar atendimento por telefone na Superintendência Regional da Paraíba durante todo o horário de funcionamento do Órgão; 4) contratar um sistema on-line mais operante; 5) elaborar relatórios semestrais e afixar um resumo nos quadros de aviso da Superintendência e Unidades Locais; 6) e realizar uma pesquisa de satisfação em relação à Ouvidoria anualmente.

A regulação e implantação de Ouvidorias Públicas colaboram para o fortalecimento da Administração Pública por funcionar como ferramenta de controle social à disposição de qualquer cidadão. Percebe-se, portanto, que com um sistema de Ouvidoria eficiente toda a gestão do órgão público sai ganhando e, principalmente, os usuários externos, já que terão suas demandas mais bem atendidas, proporcionando melhor qualidade de vida para todos os envolvidos direta ou indiretamente na gestão pública.

\section{REFERÊNCIAS}

ALEXANDRINO, Marcelo; PAULO, Vicente. Direito Administrativo descomplicado. 20 ed. revista e atualizada. Rio de Janeiro: Forense; São Paulo: Método, 2012.

BRASIL. Constituição da República Federativa do Brasil: promulgada em 5 de outubro de 1988. 
Lei $n^{\circ} 10.233$, de 5 de junho de 2001. Dispõe sobre a reestruturação dos transportes aquaviário e terrestre, cria o Conselho Nacional de Integração de Políticas de Transporte, a Agência Nacional de Transportes Terrestres, a Agência Nacional de Transportes Aquaviários e o Departamento Nacional de Infra-Estrutura de Transportes, e dá outras providências. Disponível em: http://www.planalto.gov.br/ccivil_03/leis/LEIS_2001/L10233.htm. Acesso em: 22 dez. 2015.

. Lei $\mathrm{n}^{\circ} 12.528$, de 11 de novembro de 2001. Cria a Comissão Nacional da Verdade no âmbito da Casa Civil da Presidência da República. Disponível em: www.planalto.gov.br/ccivil_03/_ato2011-2014/2011/lei/l12528.htm. Acesso em: 5 dez. 2015.

Decreto $n^{\circ} 8.243$, de 23 de maio de 2014. Institui a Política Nacional de Participação Social - PNPS e o Sistema Nacional de Participação Social - SNPS, e dá outras providências. Disponível em: http://www.planalto.gov. br/ ccivil_03/_Ato2011-2014/2014/Decreto/D8243.htm. Acesso em: 4 dez. 2015.

CHIAVENATO, Idalberto. Introdução à Teoria Geral da Administração. 6. ed. Rio de Janeiro: Campus, 2000.

CONTROLADORIA-GERAL DA UNIÃO; OUVIDORIA-GERAL DA UNIÃO. Orientações para implantação de uma unidade de Ouvidoria: rumo ao sistema participativo (Coleção OGU, Cartilha 1). Brasília: Controladoria-Geral da União; Ouvidoria-Geral da União, 2012 a. Disponível em: www.cgu.gov. br/Publicacoes/ColecaoOGU/index.asp. Acesso em: 4 dez. 2015.

DE MARIO, Camila Gonçalves; MORETTI, Ricardo de Sousa. Ouvidorias Públicas Municipais no Brasil: Possibilidade e Desafios (s/d). Disponível em: http://www. ibdu.org.br/imagens/OuvidoriasPublicasMunicipaisnoBrasil.pdf. Acesso em: 4 dez. 2015.

Ouvidorias Públicas Municipais no Brasil. Jundiaí: Paco Editorial, 2011.

GOMES, Manoel Eduardo Alves Camargo e. Do instituto do Ombudsman à construção das Ouvidorias Públicas no Brasil. In: LYRA, Rubens Pinto. Autônomas x Obedientes. A Ouvidoria Pública em debate. João Pessoa: UFPB, 2004.

GOUVEIA, Doriel Veloso. Ouvidoria viva. João Pessoa: Ministério Público da Paraíba, 2013.

LYRA, Rubens Pinto. A Ouvidoria Pública no Brasil: Modelos em disputa. João Pessoa: UFPB, 2014.

OLIVEIRA, João Elias. Ouvidoria Pública Brasileira: A evolução de um modelo único. 2010. Disponível em: https:// ouvidoria.ufg.br/n/29905-ouvidoria-publica-brasileira-a-evolucao-de-em-modelo-unicoPALUDO, Augustinho. Administração Pública - Questões. 2 ed. Editora Método, 2014. Acesso em: 4 dez. 2015.

PEREIRA, Luiz Carlos Bresser. Instituições, bom Estado e reforma da gestão pública. Revista Eletrônica sobre a Reforma do Estado. Salvador, n. 01, 2005. In: DE MARIO, Camila Gonçalves. Ouvidorias Públicas Municipais no Brasil. Jundiaí: Paco Editorial, 2011.

ROMÃO, José Eduardo Elias. Ouvidorias Públicas e Lei de Acesso à Informação. Disponível em: http://www.confea. org.brl. Acesso em: 1 dez. 2015.

SANTANA, Herick Santos. O controle externo da Administração Pública. Artigo publicado em fev. 2014. Disponível em: http://jus.com.br/artigos/26798/o-controle-externo-da-administracao-publica-no-brasil/2. Acesso em: 18 nov. 2015

SANTOS, Raimundo Nonato Silva. Juiz Ouvidor Regional Eleitoral do Ceará. A Ouvidoria e a Lei de Acesso à Informação: Novas Competências e Atribuições. Fortaleza, jun. 2012. Disponível em: http://www.tre-pr.jus.br/arquivos/a-ouvidoria-e-a-lei-e-acesso-a-informacao. Acesso em: 1 dez. 2015 